\title{
A COMPARATIVE STUDY OF HIGH SENSITIVITY C-REACTIVE PROTEIN (HS-CRP) AND GLYCEMIC MARKERS IN TYPE 2 DIABETES MELLITUS
}

\author{
Shehar Bano Imran, Shabnam Khawaja*, Sadia Taj, Afshan Khanum, Qasim Ahmed \\ Fatima Memorial Hospital, Lahore Pakistan, *National Institute of Blood Disease and Bone Marrow Transplantation, Karachi Pakistan
}

\section{ABSTRACT}

Objective: To determine the relationship between high sensitivity CRP (hs-CRP) and glycemic markers in samples of individuals with diabetes.

Study Design: Cross sectional study.

Place and Duration of Study: Fatima Memorial Hospital Lahore, from Feb to Aug 2019.

Methodology: Consecutive patients aged 18-65 years coming for screening of diabetes mellitus (DM) were included. Blood sample for plasma glucose and glycated hemoglobin (HbA1c), high sensitivity CRP (hs-CRP) were analyzed.

Results: Total 93 subjects were included, out of which 42 (45.2\%) were males and 51 (54.8\%) were females with the mean age of $48.3 \pm 12$ years and $42.6 \pm 14$ years respectively. Median concentration of hs-CRP in males and females was 0.7 (IQR1.2) $\mathrm{mg} / \mathrm{L}$ and $0.6(\mathrm{IQR} 1.4) \mathrm{mg} / \mathrm{L}(p$-value $=0.844)$ respectively. A significant positive correlation was observed between hs-CRP levels, HBA1c with $\mathrm{r}=0.205(p=0.05)$ and fasting plasma glucose (FPG) with $\mathrm{r}=0.225 \quad(p=0.03)$. However, no significant relationship was found between hs-CRP and age, BMI, waist circumference and systolic blood pressure (SBP) and diastolic blood pressure (DBP), cholesterol, LDL-cholesterol, triglycerides (TG), HDL-cholesterol.

Conclusion: HbA1c and fasting plasma glucose is significantly associated with hs-CRP. This implies a significant relation between inflammation and glycemic markers. This leads to the conclusion that patients with diabetes and high hs-CRP need further evaluation, follow-up and therapy for inflammation compared to those with low hs-CRP.

Keywords: High-sensitivity C-reactive protein, Diabetes mellitus, HbA1c, Metabolic syndrome.

How to Cite This Article: Imran SB, Khawaja S, Taj S, Khanum A, Ahmed Q. A Comparative Study of High Sensitivity C-Reactive Protein (HS-CRP) And Glycemic Markers in Type 2 Diabetes Mellitus. Pak Armed Forces Med J 2021; 71(5): 1651-1655. doi: https://doi.org/10.51253/pafmj.v71i5.4918

\footnotetext{
This is an Open Access article distributed under the terms of the Creative Commons Attribution License (https://creativecommons.org/licenses/by-nc/4.0/), which permits unrestricted use, distribution, and reproduction in any medium, provided the original work is properly cited.
}

\section{INTRODUCTION}

There is well-documented evidence that inflammation plays an important role in atherosclerosis and is one of the vital risk factors in the development of cardiovascular diseases (CVD). ${ }^{1,2}$ There are many systemic markers available for the diagnosis of inflammation, among them high-sensitivity C-reactive protein (hs$\mathrm{CRP}$ ) is considered a promising marker. In comparison to numerous other biomarkers that reveal the pathophysiology of inflammation and insulin resistance, hsCRP assessment is economical, standardized and widely available. Many studies have reported a strong relationship between hs-CRP and coronary heart disease (CHD) even in non-diabetic population. . $^{3-5}$ On the other hand patients with type 2 diabetes have shown significantly increased risk for developing CHD and majority of them die with CHD. ${ }^{6}$ The risk of major cardiovascular events in patients with type 2 diabetes without history of CHD is comparable with the non-diabetic patients with history of chronic heart disease. High

Correspondence: Dr Shehar Bano Imran, Department of Pathology, Fatima Memorial Hospital, Lahore Pakistan

Received: 05 May 2020; revision received: 05 Oct 2020; accepted: 19 Oct 2020 levels of hs-CRP have been associated with the development of CHD in diabetes. ${ }^{7}$ However, there are only few studies that show the relation of hs-CRP with the level of glycemic control in patients with diabetes and very little is known about this in Asian-Pakistani population-a high risk population.

Furthermore, elevated levels of hs-CRP can also lead to the development of the metabolic syndrome. Studies show that adding hs-CRP to the definition of metabolic syndrome will increase its predictive power for the diagnosis of cardiovascular disease (CVD) and diabetes mellitus. ${ }^{8}$ Metabolic syndrome is a group of risk factors that can lead to CVD and DM so the question arises whether hs-CRP be added to the definition of metabolic syndrome or not? Therefore, we determined the association of hs-CRP levels with glycemic markers in patients with diabetes.

\section{METHODOLOGY}

This was a cross sectional study conducted in department of Pathology, Fatima Memorial Hospital Lahore, from February to August 2019. The study was conducted after taking approval from institution's ethics review committee (FMH-01-2020-IRB-720-M). 
Consecutive sampling technique was used. Sample size was calculated as a minimum sample size of 85 was selected using 5\% level of significance $95 \%$ confidence interval, $8 \%$ margin of error and $16.98 \%$ prevalence of type II diabetes mellitus.

Inclusion Criteria: All the subjects aged 18-65 years who were referred for screening of diabetes, at the Clinical Laboratory of FMH were included in the study, after informed consent.

Exclusion Criteria: Subjects who were taking medications affecting glucose or $\mathrm{HbA1c}$ level were excluded from the study. Subjects with recent history (15 days) of inflammation or sepsis were also excluded from this study.

Demographic details weight, height, waist circumference, smoking history and family history of diabetes were recorded on a preformed questionnaire. Blood samples were collected for HbA1c and glucose. Samples for fasting plasma glucose (FPG) were collected after a minimum of 8 hours of fasting. Whole blood $\mathrm{HbA1c}$ was analyzed by immunoassay method (NGSP certified and traceable to the DCCT reference method) on Cobas c311 chemistry analyzer (Roche). Cutoffs for $\mathrm{HbA1}$ cwere normal $\leq 5.7 \%$, prediabetes $5.7-6.4 \%$, and diabetic $\geq 6.5 \% .{ }^{9}, 10$ Plasma glucose was mea-sured by hexokinase method on Cobas c311 chemistry analyzer (Roche). Cutoffs for FPG were, normal $<100 \mathrm{mg} / \mathrm{dl}$, prediabetes $100-125 \mathrm{mg} / \mathrm{dl}$ and diabetic $\geq 126 \mathrm{mg} / \mathrm{dl}$. System performance was assessed using three levels of quality control i.e. low, medium and high. Levels of hs-CRP $<1,1-3$, and $>3 \mathrm{mg} / \mathrm{L}$ have been defined as lower, moderate, and higher cardiovascular risk.

Subjects were labeled normal weight, overweight and obese according to the criteria proposed for Asian populations by International Association for the Study of Obesity and International Obesity Task Force of World Health Organization (WHO) 2001.11,12 Out of 93 patients, metabolic syndrome parameters HDL-Cholesterol and Triglyceride (TG) were available only for 37 patients.

Normality of the continuous/quantitative variables was assessed by Kolmogorov Smirnov test. Mean \pm SD or Median (IQR) were reported for quantitative variables depending upon the distribution. Frequency (\%) for the categorical variables was reported. Before the application of all the inferential statistics, assumptions were checked, and appropriate tests were applied according to the situation. Continuous variables by gender were compared using independent sample t-test/Mann Whitney U. Data was stratified according to the hs-CRP categories (low, average, high risk) and DM (Diabetic, Non-diabetic and Impaired). Gender, Hs-CRP and DM category wise comparison with categorical demographic variables was done by Fisher's Exact Test/Chi square/likelihood test. Continuous variables by hs-CRP and DM category was compared by ANOVA/Kruskal Wallis H Test. Pearson correlation coefficients/spearman's rank correlation ( $p$-value) and partial correlation coefficient were calculated to assess the association of hs-CRP with demographic data and laboratory parameters.

\section{RESULTS}

A total of 93 patients were included, out of which $42(45.2 \%)$ were males and 51(54.8\%) were females with the mean age of $48.3 \pm 12$ years and $42.6 \pm 14$ years respectively as shown in Table-I. The mean weight of males and females was $81.0 \pm 12.3 \mathrm{~kg}, 72.9 \pm 15 \mathrm{~kg}$ $(p$-value $=0.007)$ and mean waist in males and females $37.5 \pm 3.9 \mathrm{~cm}, 33.3 \pm 4.9 \mathrm{~cm}(p$-value $=0.0001)$ respectively. Median concentration of hs-CRP in males and females was 0.7 (IQR1.2) $\mathrm{mg} / \mathrm{L}$ and 0.6 (IQR1.4) $\mathrm{mg} / \mathrm{L}$ $(p$-value $=0.844)$ respectively. Males had higher fasting blood glucose, HbA1c, TG and LDL cholesterol as compared to female with mean in male and females being $105 \pm 26.6 \mathrm{mg} / \mathrm{dL}, 101 \pm 26 \mathrm{mg} / \mathrm{dL}$ ( $p$-value= $0.480), 6.1 \%$ (IQR1.10), 5.9\% (IQR 0.80) ( $p$-value=0.139), mean $172 \pm 77 \mathrm{mg} / \mathrm{dL}, 142 \pm 69 \mathrm{mg} / \mathrm{dL}$ ( $p$-value= $0.252)$, mean $110 \pm 36 \mathrm{mg} / \mathrm{dL}, 103 \pm 39 \mathrm{mg} / \mathrm{dL}$ ( $p$-value $=0.57$ ) respectively. While females had higher BMI, cholesterol and HDL-cholesterol compared to males with mean of females and males being $28.4 \pm 6.5 \mathrm{mg}$ $/ \mathrm{dL}, 27.3 \pm 5.7 \mathrm{mg} / \mathrm{dL}$ ( $p$-value=0.39), $173 \pm 32 \mathrm{mg} / \mathrm{dL}$, $169 \pm 36 \mathrm{mg} / \mathrm{dL}(p$-value $=0.76), 43.5 \pm 8.0 \mathrm{mg} / \mathrm{dL}, 38 \pm$ 6.4 respectively ( $p$-value $=0.05$ ) as shown in Table-II.

Patients were categorized into low, moderate and high cardiovascular risk groups is shown in the TablesIII \& IV.

The mean age of low cardiovascular risk group was $44 \pm 13.8$ years, the mean age of average cardiovascular risk group was $48 \pm 14.8$ years, whereas the mean age of high cardiovascular risk group was $43 \pm$ 12.8 years with more females in high risk group i.e., 9 $(9.7 \%)$ compared to males i.e., 5 (5.4\%). It was observed that pati-ents in high cardiovascular risk category had higher mean BMI $(29.2 \pm 3.7) \mathrm{kg} / \mathrm{m}^{2}$ and higher mean waist $(36.6 \pm 4.3) \mathrm{cm}$. Out of total 47 obese patients, 10 were in high risk category whereas no one with normal waist were present in high risk category.

High cardiovascular risk group patients also had higher FPG with median 105 (IQR47.2) $\mathrm{mg} / \mathrm{dL}$ and 
High Sensitivity C-Reactive Protein and Glycemic Markers

Table-I: Demographic details of study population.

\begin{tabular}{|c|c|c|c|c|}
\hline Variables & $\begin{array}{c}\text { Patients with } \\
\text { Diabetes }\end{array}$ & Impaired Diabetes & $\begin{array}{c}\text { Individuals } \\
\text { Without Diabetes }\end{array}$ & $p$-value \\
\hline Age (years) & $48.5 \pm 11.5$ & $48.5 \pm 14.2$ & $34.9 \pm 10.6$ & $<0.001$ \\
\hline \multicolumn{5}{|l|}{ Gender } \\
\hline Male & $14(15.1 \%)$ & $19(20.4 \%)$ & $9(9.7 \%)$ & \multirow{2}{*}{0.549} \\
\hline Female & $12(12.9 \%)$ & $25(26.9 \%)$ & $14(15.1 \%)$ & \\
\hline \multicolumn{5}{|l|}{ Body Mass Index (BMI) } \\
\hline Normal & $4(4.3 \%)$ & $6(6.5 \%)$ & $6(6.5 \%)$ & \multirow{3}{*}{0.705} \\
\hline Overweight & $10(10.8 \%)$ & $14(15.1 \%)$ & $6(6.5 \%)$ & \\
\hline Obese & $12(12.9 \%)$ & $24(25.8 \%)$ & $11(11.8 \%)$ & \\
\hline Waist Circumference $(\mathrm{cm})$ & $34.69 \pm 4.48$ & $36.136 \pm 5.68$ & $34.174 \pm 3.92$ & 0.182 \\
\hline Hypertensive & $7(7.5 \%)$ & $16(17.2 \%)$ & $2(2.2 \%)$ & 0.053 \\
\hline Blood pressure ( BP): Systolic, $(\mathrm{mm} \mathrm{Hg})$ & $122.5(30)$ & $120(27.5)$ & $120(10)$ & 0.275 \\
\hline Blood pressure (BP): Diastolic (mm Hg) & $80(15.75)$ & $80(10)$ & $80(5)$ & 0.103 \\
\hline \multicolumn{5}{|l|}{ Smoking } \\
\hline Yes & $8(8.6 \%)$ & $5(5.4 \%)$ & $6(6.5 \%)$ & \multirow{2}{*}{0.104} \\
\hline No & $18(19.4 \%)$ & $39(41.9 \%)$ & $17(18.3 \%)$ & \\
\hline \multicolumn{5}{|l|}{ Family History of Diabetes Mellitus } \\
\hline Yes & $16(17.2 \%)$ & $30(32.3 \%)$ & $11(11.8 \%)$ & \multirow{2}{*}{0.267} \\
\hline No & $10(10.8 \%)$ & $14(15.1 \%)$ & $12(12.9 \%)$ & \\
\hline
\end{tabular}

Continuous variables with normal distribution are presented in form of Mean \pm SD, Continuous variables with non-normal distribution are presented in form of Median (IQR), Categorical variables are presented in form of $n(\%)$.

Table-II: Biochemical variables of study population.

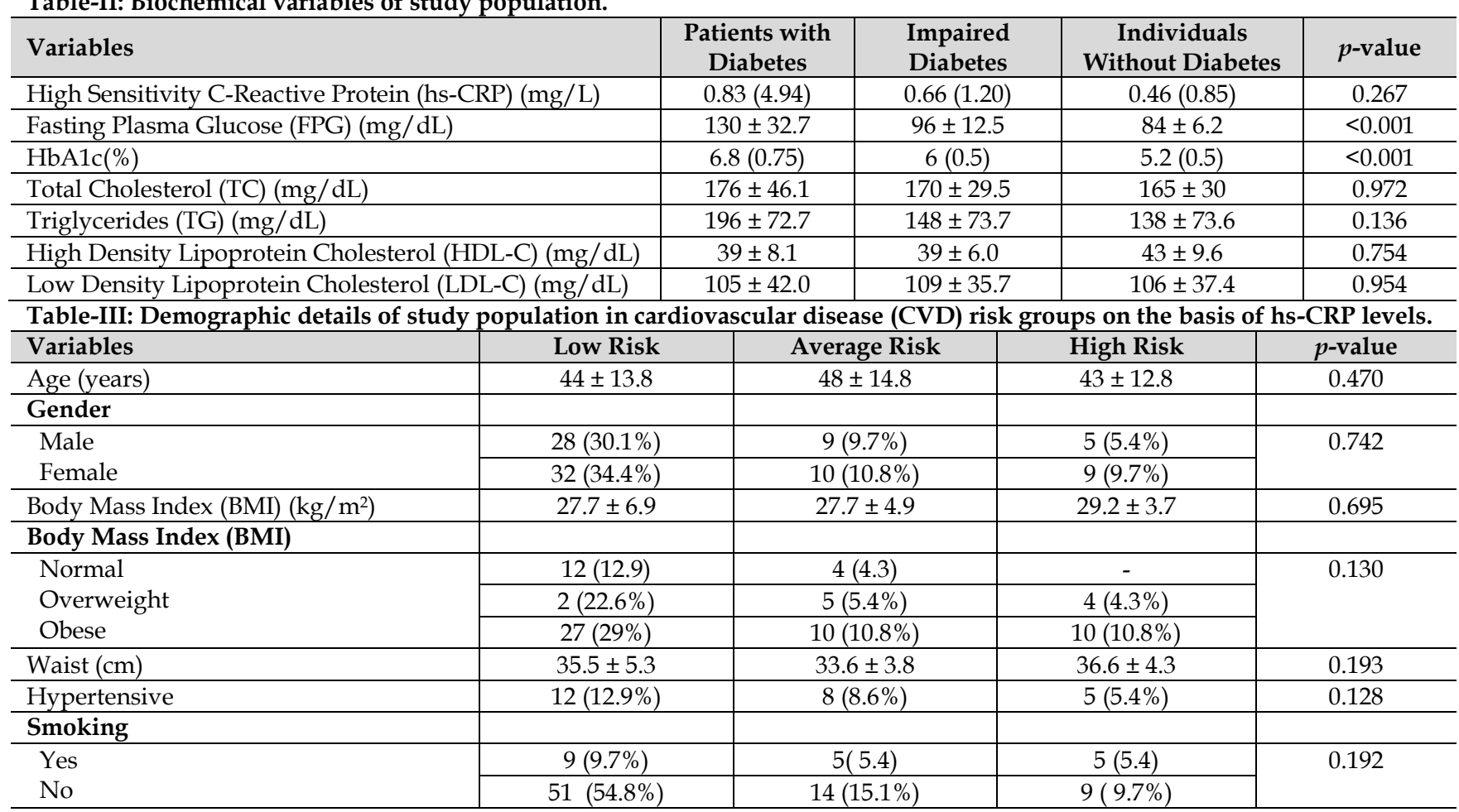

higher HbA1c levels with median 6.6 (IQR 2.0) \%, whereas total cholesterol, TG and LDL-cholesterol were high in average cardiovascular risk group compared to high cardiovascular risk group. Comparison between two groups is shown in the Table-V.

The median hs-CRP levels were high in diabetic group while no statistically significant difference was seen in hs-CRP levels between diabetic, pre-diabetic and non-diabetic groups.

Among 93 patients, metabolic syndrome parameters were available only for 37 patients among those, metabolic syndrome was present in $\mathrm{n}=17$, out of which 4 (\%) were diabetic, $11(29.7 \%)$ were pre-diabetic and 2 $(5.4 \%)$ were non-diabetics. Metabolic syndrome was 
absent in 20 out of which $7(18.9 \%)$ were diabetics, 8 $(21.6 \%)$ were pre-diabetic, $5(13.5 \%)$ were non-diabetics. Patients with metabolic syndrome had median hsCRP of 0.77 (IQR 1.62) and for non-metabolic syndrome it was 0.69 (IQR 1.27). There was no significant difference in the hs-CRP levels in patients with metabolic synd-rome and non-metabolic syndrome.

A significant positive correlation was observed between hs-CRP levels, HBA1c with $\mathrm{r}=0.205(p=0.05)$ and FPG with $\mathrm{r}=0.225 \quad(p=0.03)$. However, no significant relationship was found between hs-CRP and age, BMI, waist circumference and SBP and DBP, cholesterol, LDL-cholesterol, TG, HDL-cholesterol. also reported a statistically significant positive correlation between hs-CRP and HbA1c with $\mathrm{r}=0.22$, $p$-value $=0.001$. As we shown a positive correlation between hsCRP, FPG and HbA1c, it has been reported that patients with diabetes who had poorer glycemic control had higher hs-CRP levels. ${ }^{19}$ The results of the present study favor the finding that among diabetic population, higher levels of glycemic markers i.e. FPG and HbA1c correlates well with significantly higher hsCRP levels. Based on these findings we suggest that the inflammation may not only be associated with development of diabetes, but also associated with poor glycemic control once diabetes is established. Poor

Table -IV: Biochemical variables of study population in cardiovascular disease risk groups on the basis of hs-CRP levels.

\begin{tabular}{|c|c|c|c|c|c|c|}
\hline \multicolumn{2}{|c|}{ Variables } & \multicolumn{2}{|c|}{ Low Risk } & Average Risk & High Risk & $p$-value \\
\hline \multicolumn{2}{|c|}{ Fasting plasma glucose (FPG)(mg/dL) } & \multicolumn{2}{|c|}{$93(21.25)$} & $98(22)$ & $105(47.2)$ & 0.034 \\
\hline \multicolumn{2}{|c|}{$\mathrm{HbA1c}(\%)$} & \multicolumn{2}{|c|}{$5.9(0.80)$} & $6.1(0.90)$ & $6.6(2.0)$ & 0.105 \\
\hline \multicolumn{2}{|c|}{ Triglycerides $(\mathrm{TG})(\mathrm{mg} / \mathrm{dL})$} & \multicolumn{2}{|c|}{$145 \pm 56$} & $192 \pm 99$ & $131 \pm 12.5$ & 0.110 \\
\hline \multicolumn{2}{|c|}{ High Density Lipoprotein Cholesterol (HDL)(mg/dL) } & \multicolumn{2}{|c|}{$38.7 \pm 5.2$} & $42 \pm 9.3$ & $43 \pm 11.3$ & 0.436 \\
\hline \multicolumn{2}{|c|}{ Low Density Lipoprotein Cholesterol (LDL)(mg/dL) } & \multicolumn{2}{|c|}{$104 \pm 35$} & $112 \pm 41$ & $109 \pm 41$ & 0.847 \\
\hline \multicolumn{2}{|c|}{ Total Cholesterol $(\mathrm{TC})(\mathrm{mg} / \mathrm{dL})$} & $165 \pm$ & & $177 \pm 40$ & \begin{tabular}{l|r|} 
& $171 \pm 38.2$ \\
\end{tabular} & \begin{tabular}{l|l|} 
& 0.695 \\
\end{tabular} \\
\hline \multicolumn{7}{|c|}{ Table-V: Comparison of diabetic groups with low, medium and high-risk cardiovascular disease groups based on hs-CRP levels } \\
\hline & & & \multicolumn{4}{|c|}{ Diabetes Mellitus (DM) categories } \\
\hline & & & & \begin{tabular}{l|l} 
ients with \\
liabetes
\end{tabular} & \begin{tabular}{c|} 
Individuals \\
without diabetes
\end{tabular} & Impaired \\
\hline \multirow{3}{*}{$\begin{array}{l}\text { High Sensitivity C- } \\
\text { Reactive Protein } \\
\text { Hs-CRP category }\end{array}$} & \multicolumn{2}{|c|}{ Low Risk cardiovascular disease group } & & $4(15.1 \%)$ & $17(18.3 \%)$ & $29(31.2 \%)$ \\
\hline & \multirow{2}{*}{\multicolumn{2}{|c|}{$\begin{array}{l}\text { Average Risk cardiovascular disease group } \\
\text { High Risk cardiovascular disease group }\end{array}$}} & & $5(5.4 \%)$ & $4(4.3 \%)$ & $10(10.8 \%)$ \\
\hline & & & & $7(7.5 \%)$ & $2(2.2 \%)$ & $5(5.4 \%)$ \\
\hline
\end{tabular}

\section{DISCUSSION}

Hs-CRP is an inflammatory marker; it plays a significant role in the development of insulin resistance (IR). Many studies have suggested that inflammation is linked with insulin resistance that plays a vital role in the pathogenesis of type 2 diabetes mellitus as well as in atherosclerosis. ${ }^{13,14}$ Conversely, hyperglycemia by itself may induce inflammation and contribute in the development of complications in patients with diabetes. ${ }^{15}$ Studies have shown that hs-CRP levels are higher in patients with diabetes. ${ }^{16}$ Tutuncu et al, reported a positive correlation between hs-CRP levels and with other glycemic and insulin resistance parameters. ${ }^{17} \mathrm{In}$ this cross-sectional study the association of hs-CRP with other metabolic markers such as FPG, HbA1c, TC, LDL-cholesterol, HDL-cholesterol, TG and BMI were evaluated. Similar study was done by Mahajan et al, they reported median hs-CRP levels in diabetic patients $2.68 \mathrm{mg} / \mathrm{dL}$, which was significantly higher compared to non-diabetics $1.58 \mathrm{mg} / \mathrm{dL}$ ( $p$-value $\leq 0.0001) .{ }^{18}$

We also found a significant positive correlation between hs-CRP levels and HbA1c $(\mathrm{r}=0.205)$ ( $p$-value $=0.05)$ and FPG $(\mathrm{r}=0.225)(p$-value=0.03). Mahajan et al, glycemic control further leads to inflammation. Better glycemic control may lower inflammation and consequently reduce the risk of cardiovascular events. As inflammation leads to hyperglycemia, then management of inflammation may help improve glycemic control. The findings of this study further support the relation between glycemic control and systemic inflammation in patients with diabetes.

In our study we observed that patients in high cardiovascular risk group (hs-CRP $>3 \mathrm{mg} / \mathrm{L}$ ) were of younger age with mean age $43 \pm 12.8$ years, their median FPG was 105 (IQR47.2) mg/dL which fall into impaired diabetic category and they had higher median HbA1c levels 6.6 (IQR 2.0) \% as compared to average and low cardiovascular group. So, this could be said that patients who have elevated hs-CRP at younger age are more prone to develop cardiovascular disease early as compared to patients who have low levels of hsCRP at same age.

Elevation of hs-CRP at younger age is like a double-edged sword, one causes the development of diabetes and other is responsible for atherosclerosis. In our study, we found that patients with raised hs-CRP 


\section{High Sensitivity C-Reactive Protein and Glycemic Markers}

had impaired FPG and higher HbA1c levels further analysis showed that they also had raised LDL-cholesterol and TC. Diagnosing the patients at younger age group by analyzing hs-CRP levels especially in highrisk population could be beneficial in prevention and early treatment of diabetes and atherosclerosis which decreases the risk for cardiovascular disease. Similar study done by Effoe et al, who did age-stratified analysis, they found out that the association of hs-CRP with diabetes is stronger in patients at younger than 45 years compared with those older than 45 years. ${ }^{20}$ Gupta et al, observed premature CVD in less than 45 years of age, the majority of them $(80.8 \%)$ had high hsCRP levels with only few (3.8\%) having hs-CRP levels within the normal limits $(<1 \mathrm{mg} / \mathrm{L})(p$-value 0.00$) .{ }^{21}$

There was no significant difference seen in hsCRP levels in patients with metabolic syndrome and non-metabolic syndrome. This may be due to the fact that metabolic syndrome parameters were available only in $37(39.7 \%)$ patients, it was the limitation of our study. Furthermore, this study was conducted at single institute with a small sample size. The strength of the study was a strict inclusion criterion of patients and completion of study on time.

\section{CONCLUSION}

This study reveals that higher levels of glycemic markers are significantly associated with increased levels of hsCRP. The results suggest note worthy relationship between inflammation and glycemic control in diabetic population. It can be important to realize that newly diagnosed patients with diabetes with high levels of hs-CRP need more intensive therapy than those with low levels of hs-CRP.

\section{Conflict of Interest: None.}

\section{Authors' Contribution}

SI: Designed, conception, planning and execute the study, SK: Data entry, data interpretation, preparation of data, ST: Data entry, data interpretation, preparation of data, AK: Statistical analysis, QA: Critical review.

\section{REFERENCES}

1. Mozos I, Malainer C, Horbańczuk J, Gug C, Stoian D, Luca CT, et al. Inflammatory markers for arterial stiffness in cardiovascular diseases. Front Immunol 2017; 8(2): 1058-1062.

2. Taleb S. Inflammation in atherosclerosis. Arch Med Sci Atheroscler Dis 2016; 109(12): 708-715.

3. Tayefi M, Tajfard M, Saffar S, Hanachi P, Amirabadizadeh AR, Esmaeily $\mathrm{H}$, et al. hs-CRP is strongly associated with coronary heart disease (CHD): A data mining approach using decision tree algorithm. Comput Methods Programs Biomed 2017; 141(1): 105-109.
4. Munkhaugen J, Otterstad JE, Dammen T, Gjertsen E, Moum T, Husebye $\mathrm{E}$, et al. The prevalence and predictors of elevated C-reactive protein after a coronary heart disease event. Eur J Prev Cardiol 2018; 25(9): 923-931.

5. Zhuang Q, Shen C, Chen Y, Zhao X, Wei P, Sun J. Association of high sensitive C-reactive protein with coronary heart disease: a Mendelian randomization study. BMC Med Genet 2019; 20(1): 170-175.

6. Faghihi-Kashani S, Bonnet F, Hafezi-Nejad N, Heidari B, Nargesi AA, Sheikhbahaei S, et al. Fasting hyperinsulinaemia and 2-h glycaemia predict coronary heart disease in patients with type 2 diabetes. J Diabet 2016; 42(1): 55-61.

7. Ridker PM, Glynn RJ, Hennekens CH. C-reactive protein adds to the predictive value of total and HDL cholesterol in determining risk of first myocardial infarction. Circulat 1998; 97(20): 2007-2011.

8. Kazemi-Bajestani SM, Tayefi M, Ebrahimi M, Heidari-Bakavoli AR, Moohebati M, Parizadeh SM, et al. The prevalence of meta-bolic syndrome increases with serum high sensitivity C-reactive protein concentration in individuals without a history of cardio-vascular disease: a report from a large Persian cohort. Ann Clin Lab Sci 2017; 54(6): 644-648.

9. Alonso GT, Pyle L, Frohnert B. Change in hemoglobin A1c one year following the 2014 American Diabetes Association guideline update. Diabetes Res Clin Pract 2017; 129(1): 169-72.

10. Organization WH. Use of glycatedhaemoglobin $(\mathrm{HbA} 1 \mathrm{c})$ in diagnosis of diabetes mellitus: abbreviated report of a WHO consultation. Geneva: World Health Organization; 2011, [Internet] Available at: https://apps.who.int/iris/handle/10665/70523

11. Choo V. WHO reassesses appropriate body-mass index for Asian populations. Lancet 2002; 360(9328): 235-240.

12. Gill T. Epidemiology and health impact of obesity: an Asia Pacific perspective. Asia Pac J Clin Nutr 2006; 15(Suppl-1): 3-14.

13. Yuan T, Yang T, Chen H, Fu D, Hu Y, Wang J, et al. New insights into oxidative stress and inflammation during diabetes mellitus-accelerated atherosclerosis. J Redox 2019; 20(2): 247-260.

14. Donath MY, Shoelson SE. Type 2 diabetes as an inflammatory disease. Nat Rev Immunol 2011; 11(2): 98-107.

15. Aronson D, Bartha P, Zinder O, Kerner A, Shitman E, Markiewicz W, et al. Association between fasting glucose and C-reactive protein in middleeaged subjects. Diabet Med 2004; 21(1): 39-44.

16. Festa A, D'Agostino R, Tracy RP, Haffner SM. Elevated levels of acute-phase proteins and plasminogen activator inhibitor-1 predict the development of type 2 diabetes: the insulin resistance atherosclerosis study. Diabet 2002; 51(4): 1131-1137.

17. Tutuncu Y, Satman I, Celik S, Dinccag N, Karsidag K, Telci A, et al. A comparison of hs-CRP levels in new diabetes groups diagnosed based on FPG, 2-hPG, or HbA1c criteria. J Diabet Res 2016; 2016(11): $1-9$.

18. Mahajan A, Tabassum R, Chavali S, Dwivedi OP, Bharadwaj M, Tandon N, et al. High-sensitivity C-reactive protein levels and type 2 diabetes in urban North Indians. J Clin Endocrinol Metab 2009; 94(6): 2123-2127.

19. Elimam H, Abdulla AM. Inflammatory markers and control of type 2 diabetes mellitus. Diabetes Metab Syndr 2019; 13(1): 800-804.

20. Effoe VS, Correa A, Chen H, Lacy ME, Bertoni AG. High-sensitivity C-reactive protein is associated with incident type 2 diabetes among African Americans: the Jackson Heart Study. Diabetes Care 2015; 38(9): 1694-700.

21. Gupta S, Gupta VK, Gupta R, Arora S, Gupta V. Relationship of highsensitive C-reactive protein with cardiovascular risk factors, clinical presentation and angiographic profile in patients with acute coronary syndrome: An Ind Perspective. Ind Heart J 2013; 65(3): 359-365. 